\title{
Thiopurine S-methyltransferase genetic polymorphism in the Thai population
}

\author{
Somrudee Srimartpirom, ' Wongwiwat Tassaneeyakul, ${ }^{2}$ Veerapol Kukongviriyapan' \& Wichittra Tassaneeyakul' \\ ${ }^{1}$ Department of Pharmacology, Faculty of Medicine and ${ }^{2}$ Department of Toxicology, Faculty of Pharmaceutical Sciences, Khon Kaen \\ University, Khon Kaen 40002, Thailand.
}

\author{
Correspondence \\ Dr Wichittra Tassaneeyakul, \\ Department of Pharmacology, Faculty \\ of Medicine, Khon Kaen University, \\ Khon Kaen 40002, Thailand. \\ Tel/Fax: 6643348397 \\ E-mail: wichitt@kku.ac.th

\section{Keywords} \\ genetic polymorphism, Thai, \\ thiopurine S-methyltransferase, TPMT

\section{Received} \\ 2 October 2003 \\ Accepted \\ 30 January 2004
}

\begin{abstract}
Aims
To determine the incidence of the thiopurine S-methyltransferase (TPMT) genetic polymorphism in the Thai population.

Methods

Genomic DNAs were isolated from peripheral blood leucocytes of 200 healthy Thais. The frequencies of five allelic variants of the TPMT gene, TPMT*2, *3A, *3B, *3C and *6 were determined using allele specific polymerase chain reaction (PCR) or PCRRestriction fragment length polymorphism technique.
\end{abstract}

\section{Results}

Of the 200 Thai subjects participating in this study, 181 subjects (90.5\%) were homozygous for TPMT*1, 18 subjects $(9.0 \%)$ were heterozygous for TPMT*1/*3C. Only one subject $(0.5 \%)$ was homozygous for TPMT*3C. The frequency of TPMT*3C mutant allele was 0.050 .

\section{Conclusions}

Although the TPMT*3C is the most prevalent mutant allele in Asian populations, the frequency of this defective allele is significantly higher in Thais than has been reported in other Asian populations.

\section{Introduction}

Thiopurine methyltransferase (TPMT) is a cytosolic enzyme involved in S-methylation of aromatic and heterocyclic sulfhydryl compounds including the immunosuppressant, azathioprine, and the anticancer agents, 6-mercaptopurine and 6-thioguanine $[1,2]$. The parent thiopurine drugs are metabolized to nucleotide intermediates by hypoxanthine-guanine phosphoribosyltransferase and then further metabolized to the active metabolites, thioguanine nucleotides (TGN). Alternatively, thiopurines are metabolized to inactive Smethylated metabolites by TPMT and 6-thiouric acid by xanthine oxidase (XO), thereby decreasing the amount of drug available for activation to TGN. Negative corre- lation between the intracellular concentration of TGN and the activity of TPMT in erythrocytes has been reported [3]. Intracellular TGN concentrations have been shown to correlate with the efficacy and toxicity of thiopurines in various diseases; therefore, interpatient differences in TPMT activity can have a significant impact on the efficacy and toxicity of these medications $[4,5]$.

The human TPMT gene exhibits genetic polymorphism, and TPMT activity is inherited as an autosomal codominant trait [6]. The trimodal distribution in TPMT activity has been observed in Caucasians and AfricanAmericans with approximately $90 \%$ possessing high activity, $10 \%$ intermediate activity and $0.3 \%$ low 
activity [6]. The molecular genetic basis of the TPMT polymorphism is now well recognized. To date, more than 10 allelic variants of TPMT have been reported [7]. These variant alleles result from point mutations in the coding sequence or mutations at intron-exon splice sites [2]. TPMT*2 was the first variant allele discovered and comprises a $\mathrm{G} 238 \mathrm{C}$ transversion that resulted in the Ala80Pro amino acid substitution [8]. The TPMT*3A mutation comprises two transitions, G460A and A719G, which in turn produce the amino acid substitutions Ala154Thr and Tyr240Cys, respectively, whereas the $T P M T * 3 B$ or $T P M T * 3 C$ comprises only the G460A or A719G transition [9, 10]. Transfection of these mutant cDNAs into COS-1 cells showed a decrease in both enzyme activity and immunoreactive protein [8-10]. In Caucasians, TPMT*3A is the most prevalent deficiencyassociated allele accounting for $85 \%$ of total variant alleles, whereas TPMT*3C is the predominant deficiency-associated allele reported in Asian and African populations. In addition, $T P M T^{*} 6$, with the A539T transversion resulted in the Tyr180Phe amino acid substitution, was discovered in Korean and Japanese patients who have low TPMT activity [11, 12]. It has been reported that the frequency of this variant allele was relatively rare (i.e 0.007) in Japanese children with acute lymphoblastic leukaemia [12] but it was not detected among Caucasian populations [11, 12]. Moreover, a polymorphism in the $5^{\prime}$-flanking promoter region due to a variable number of tandem repeats (VNTR), ranging from 4 to 8 repeats, which are involved in the regulation of TPMT expression has been identified [13].

Most of the TPMT genetic polymorphism studies in Asian populations were performed in Far East Asian (i.e. Chinese, Japanese or Korean) and Southwest Asian populations (i.e. Indian, Pakistani, Sri Lankan and Nepali) $[11,14,15]$. We found only two reports about this genetic polymorphism in the Thai population $[16,17]$. Although the $T P M T^{*} 3 C$ was the most prevalent defective allele found in both reports, the frequency of this allele was more than 5-fold difference. The allele frequency was 0.053 in 75 children with acute leukaemia [16] but was only 0.010 in 100 healthy workers [17]. Heterogeneity among the Thai ethnic is well recognized, particularly those who reside in different parts of the country. The influence of migrants such as Chinese and Laos may also contribute to this uncertainty of TPMT polymorphism. In order to verify the polymorphism of TPMT in the Thai population, the present study was therefore carried out in an extended and well-defined Thai population.

\section{Materials and Methods}

Study population

Two hundred unrelated Thais (64 females, 136 males, aged $41.6 \pm 12.7$ years) were voluntarily recruited in this study. All subjects were classified as native northeastern Thai according to family history of their parents and grandparents. Subjects were healthy as defined by medical history and physical examination. Written informed consent was obtained from all subjects after they had been informed both verbally and in writing about the experimental procedures and purposes of the study. Ethical approval for this study was obtained from the Ethical Research Committee of Khon Kaen University.

\section{Detection of TPMT variants}

Five milliliters of venous blood were collected in a tube containing EDTA. Peripheral blood leucocytes were separated by centrifugation at $3000 \mathrm{~g}$ for $15 \mathrm{~min}$. Genomic DNA was purified from peripheral blood leucocytes by phenol-chloroform extraction procedure [18]. Genotype analysis of $T P M T^{*} 2$ was performed using allele specific PCR while detection of $T P M T^{*} 3 A$, $T P M T^{*} 3 B$ and $T P M T^{*} 3 C$ were carried out using PCRRFLP as previously described by Yates et al. [19]. PCR amplification was performed using a Gradient Robocycler (Stratagene ${ }^{\circledR}$, La Jolla, CA, USA). An initial denaturation step at $94{ }^{\circ} \mathrm{C}$ for $5 \mathrm{~min}$ was followed by 37 cycles consisting of denaturation step at $94{ }^{\circ} \mathrm{C}$ for $45 \mathrm{~s}$, annealing for $45 \mathrm{~s}$ at $56{ }^{\circ} \mathrm{C}$ for $T P M T^{*} 2$ or at $59^{\circ} \mathrm{C}$ for TPMT ${ }^{*} 3$, and extension at $72{ }^{\circ} \mathrm{C}$ for $45 \mathrm{~s}$. The final extension was subsequently performed at $72{ }^{\circ} \mathrm{C}$ for 10 min. For TPMT*3 determination, the resulting PCR products containing nucleotide 460 and nucleotide 719 were digested with $M w o I$, and AccI, respectively. Nested PCR was used for detection of $T M P T^{*} 6$ as previously described by Ando et al. [12]. The DNA fragments were subsequently analysed using a 3\% agarose gel electrophoresis and stained with ethidium bromide.

\section{Statistical analysis}

Subjects were genotyped and allele frequencies were calculated by counting alleles. Goodness of fit between observed and estimated genotype frequencies according to Hardy-Weinberg equilibrium was determined by the Chi-squared test. Allele frequencies in different racial populations were compared using the $Z$-test. A $P$-value of less than 0.05 was considered statistically significant. Statistical analysis of the data was performed using the Stata statistical software package (version 6, Stata Corp, TX, USA). 


\section{Results and Discussion}

The results of the genotype analysis are summarized in Table 1. Of 200 healthy Thai subjects investigated in this study, 181 subjects were homozygous for $T P M T^{*} 1$ (90.5\%; 95\%CI 85.56-94.18). Eighteen were heterozygous for $T P M T^{*} 1 / * 3 C(9.0 \%$; $95 \%$ CI $5.42-13.85)$ and one was homozygous for TPMT*3C $(0.5 \%$; 95\% CI 0.01-2.75). Similar to those previous reports in other Asian populations, none of our subjects carried $T P M T^{*} 2,3 A$ or $3 B$. Although $T P M T^{*} 6$ is a rare mutant allele found in Japanese and Korean populations, this mutant allele was not detected in the Thai population. The absence of this mutant allele in the Thai population is consistent with the results observed in South-east Asian populations [17].

Table 1

Genotype frequencies of TPMT in Thai subjects

\begin{tabular}{lcc}
\hline TPMT genotype & $\begin{array}{l}\text { Number of } \\
\text { subjects }\end{array}$ & $\begin{array}{l}\text { \% Genotype frequency } \\
(95 \% \mathrm{Cl})\end{array}$ \\
\hline$* 1 / * 1$ & 181 & $90.5(85.56-94.18)$ \\
$* 1 / * 3 C$ & 18 & $9.0(5.42-13.85)$ \\
$* 3 C / * 3 C$ & 1 & $0.5(0.01-2.75)$ \\
\hline
\end{tabular}

Genotype frequency was expressed in percentage with 95\% confidence interval shown in brackets.
The allele frequencies of $T P M T^{*} 1$ and $T P M T^{*} 3 C$ in Thai population in this study were found to be 0.950 (95\% CI 0.924-0.969) and 0.050 (95\% CI 0.0310.076), respectively (Table 2). Based on the HardyWeinberg equlibrium, the genotype frequencies for homozygous $T P M T^{*} 1$, heterozygous $T P M T^{*} 1 / * 3 C$ and homozygous $T P M T * 3 C$ were estimated to be $90.25 \%$, $9.5 \%$ and $0.25 \%$, respectively. These values are not statistically different from the actual observed frequencies (Table 1).

As shown in Table 2, the allele frequency of $T P M T^{*} 3 C$ in Thais was significantly higher than those observed in Chinese, Japanese, Taiwanese and Southwest Asians, but not significantly different from those observed in African populations. Although the frequencies of each TPMT mutant alleles previously reported in Caucasian populations were different from those observed in the Thai population, when combined, all the TPMT mutant alleles found in Caucasian populations the frequency of mutant allele observed in Thai population was comparable to those found in Caucasian populations. This finding was consistent with the recent data of Hongeng et al. [16], who reported that the frequency of $T P M T * 3 C$ observed in 75 Thai children with acute leukaemia was 0.053 . Recently, the allele frequency distribution of TPMT mutations in South-east Asian populations including Thai, Indonesian and Filipino populations have been reported [17]. Although the $T P M T^{*} 3 C$ was the only mutant allele detected in these South-east Asian populations, the frequency of this

Table 2

Comparative allele frequencies of TPMT in various populations

\begin{tabular}{|c|c|c|c|c|c|c|c|}
\hline \multirow[b]{2}{*}{ Populations } & \multicolumn{7}{|c|}{ Allele frequency } \\
\hline & $\mathrm{N}$ & $*_{1}$ & *2 & $* 3 A$ & $* 3 C$ & $* 6$ & References \\
\hline Thai & 400 & $\begin{array}{l}0.950 \\
(0.924-0.969)\end{array}$ & 0 & 0 & $\begin{array}{l}0.050 \\
(0.031-0.076)\end{array}$ & 0 & Present study \\
\hline Chinese & 384 & $0.977^{*}$ & 0 & 0 & $0.023^{*}$ & ND & [14] \\
\hline Japanese & 1044 & $0.984 * *$ & 0 & 0 & $0.016^{* *}$ & ND & [15] \\
\hline Japanese & 142 & $0.979 * *$ & 0 & 0 & 0.014 & 0.007 & [12] \\
\hline Taiwanese & 498 & $0.994 * *$ & 0 & 0 & $0.006^{* *}$ & 0 & [17] \\
\hline South-west Asians & 198 & $0.990 * *$ & 0 & $0.010 *$ & 0* & ND & [14] \\
\hline South-east Asians & 600 & 0.990* & 0 & 0 & $0.010^{*}$ & 0 & {$[17]$} \\
\hline Kenyans & 202 & 0.946 & 0 & 0 & 0.054 & ND & {$[25]$} \\
\hline Ghanaians & 434 & 0.924 & 0 & 0 & 0.076 & ND & {$[26]$} \\
\hline American Caucasians & 564 & 0.964 & 0.002 & $0.032 *$ & $0.002 * *$ & ND & [22] \\
\hline British Caucasians & 398 & 0.947 & 0.005 & $0.045^{*}$ & $0.003^{* *}$ & ND & [26] \\
\hline
\end{tabular}

$N$ represents number of alleles detected. Data in parentheses represent 95\% Cl. ND, not detected. Different from Thai population ( $* P<0.05$ and $* * P<0.005)$. 
mutant allele observed in these South-east Asians populations (i.e. 0.010) was significantly lower than that found in Thais in the present study $(0.05$; $95 \%$ CI $0.031-$ 0.076). It should be noted that the subjects who participated in the present study were native Thais, whereas Thai subjects who participated in the study by Chang [17] were Thai workers in Taiwan whose origin was not well defined. In addition, although 100 Thai workers were genotyped in Chang's study, the allele frequencies of TPMT shown in their report were analysed as mean values for South-east Asians by combining the data observed in Thai subjects with those observed in 100 Filipino and 100 Indonesian subjects. This may lead to the discrepancy in the frequency of $T P M T^{*} 3 C$ reported in their study and the present study. Our recent study with the genetic polymorphism of CYP2C19 demonstrated that the allele frequency of certain mutants was also significant difference from those previously observed in other South-east Asians [18].

Because of the absence of XO enzyme in haematopoietic tissues, TPMT appears to be the key enzyme responsible for inactivation of thiopurine drugs in these tissues, therefore the patients with TPMT deficiency may rapidly accumulate high concentration of TGN thus resulting in potentially myelotoxicity [2]. Evidence from site-directed mutagenesis and heterozygous expression demonstrate that $T P M T^{*} 3 C$ mutation leads to both reduction in catalytic activity and immunoreactive protein $[9,10]$. Consistent with these finding, the steady- state level and the degradation half-life of $\mathrm{TPMT}^{*} 3 \mathrm{C}$ protein when expressed in mammalian cells were lower than those of the wildtype protein [20]. Moreover, the TPMT activity of subject with heterozygous $T P M T^{*} 1 / * 3 C$ was almost $50 \%$ lower than that of the homozygous wild-type [21, 22]. It has been demonstrated recently that there was more than six-fold over-representing of TPMT deficiency or heterozygosity among patients developing dose-limiting haematopoietic toxicity from thiopurine drugs [23]. Results from the present study revealed that $T P M T * 3 C$ was the most prevalent mutant allele among Thai population with significantly higher frequency than other Asian populations and these suggest that at least $10 \%$ of Thai population might have an increased risk of thiopurine-induced toxicity. In fact, we have recently reported azathioprine-induced fatal myelosuppression in a renal transplant Thai recipient who carried heterozygous $T P M T^{*} 1 / * 3 C$ [24]. In agreement with the concept proposed for the Caucasians, determination of TPMT genotype before starting any thiopurine dosage regimen may also have clinical benefit to Thai patients.
We would like to thank Professor Amnuay Thithapanda, Thammasat University, Thailand for his valuable comments. This study was supported by a research grant from the Thailand Research Fund and a grant-in-aid from Faculty of Medicine, Khon Kaen University.

\section{References}

1 Krynetski EY, Evans WE. Genetic polymorphism of thiopurine Smethyltransferase: molecular mechanisms and clinical importance. Pharmacology 2000; 61: 136-46.

2 Weinshilboum RM. Thiopurine pharmacogenetics: clinical and molecular studies of thiopurine methyltransferase. Drug Metab Dispos 2001; 29: 601-5.

3 Lennard L, Lilleyman JS, Van Loon J, Weinshilboum RM. Genetic variation in response to 6-mercaptopurine for childhood acute lymphoblastic leukaemia. Lancet 1990; 336: 225-9.

4 Relling MV, Hancock ML, Rivera GK, et al. Mercaptopurine therapy intolerance and heterozygosity at the thiopurine Smethyltransferase gene locus. J Natl Cancer Inst 1999; 91: 20018.

5 Schwab M, Schaffeler E, Marx C, et al. Azathioprine therapy and adverse drug reactions in patients with inflammatory bowel disease: impact of thiopurine S-methyltransferase polymorphism. Pharmacogenetics 2002; 12: 429-36.

6 Weinshilboum RM, Sladek S. Mercaptopurine pharmacogenetics: monogenic inheritance of erythrocyte thiopurine methylatransferase activity. Am J Hum Genet 1980; 32: 651-62.

7 Coulthard SA, Hall AG. Recent advances in the pharmacogenomics of thiopurine methyltransferase. Pharmacogenomics J 2001; 1: 254-61.

8 Krynetski EY, Schuetz JD, Galpin AJ, Pui CH, Relling MV, Evans WE. A single point mutation leading to loss of catalytic activity in human thiopurine S-methyltransferase. Proc Natl Acad Sci USA 1995; 92: 949-53.

9 Tai $\mathrm{HL}$, Krynetski EY, Yates CR, et al. Thiopurine Smethyltransferase deficiency: two nucleotide transitions define the most prevalent mutant allele associated with loss of catalytic activity in Caucasians. Am J Hum Genet 1996; 58: 694-702.

10 Szumlanski C, Otterness D, Her C, et al. Thiopurine methyltransferase pharmacogenetics: human gene cloning and characterization of a common polymorphism. DNA Cell Biol 1996; 15: 17-30.

11 Otterness D, Szumlanski C, Lennard L, et al. Human thiopurine methyltransferase pharmacogenetics: gene sequence polymorphisms. Clin Pharmacol Ther 1997; 62: 60-73.

12 Ando M, Ando Y, Hasegawa Y, Shekido Y, Shimokata K, Horibe K. Genetic polymorphisms of thiopurine S-methyltransferase and 6mercaptopurine toxicity in Japanese with acute lymphoblastic leukaemia. Pharmacogenetics 2001; 11: 269-73.

13 Spire-Vayron de la Moureyre C, Debuysere H, Fazio F, et al. Characterization of a variable number tandem repeat region in the thiopurine S-methyltransferase gene promoter.

Pharmacogenetics 1999; 9: 189-98. 
14 Collie-Duguid ES, Pritchard SC, Powrie RH, et al. The frequency and distribution of Thiopurine methytransferase alleles in Caucasian and Asian populations. Pharmacogenetics 1999; 9: 37-42.

15 Kumagai K, Hiyama K, Ishioka S, et al. Allelotype frequency of the thiopurine methyltransferase (TPMT) gene in Japanese. Pharmacogenetics 2001; 11:275-8.

16 Hongeng S, Sasanakul W, Chuansumrit A, Pakakasama S, Chattananon A, Hathirat P. Frequency of thiopurine Smethyltransferase genetic variation in Thai children with acute leukemia. Med Pediatr Oncol 2000; 35: 410-4.

17 Chang JG, Lee LS, Chen CM, et al. Molecular analysis of thiopurine S-methyltransferase alleles in South- east Asian populations. Pharmacogenetics 2002; 12: 191-5.

18 Tassaneeyakul W, Tawalee A, Tassaneeyakul W, et al. Analysis of the CYP2C19 polymorphism in a North-eastern Thai population. Pharmacogenetics 2002; 12: 221-5.

19 Yates CR, Krynetski EY, Loennechen T, et al. Molecular diagnosis of thiopurine S-methyltransferase deficiency: genetic basis for azathioprine and mercaptopurine intolerance. Ann Intern Med 1997; 126: 608-14.

20 Tai HL, Fessing MY, Bonten EJ, et al. Enhanced proteasomal degradation of mutant human thiopurine S- methyltransferase (TPMT) in mammalian cells: mechanism for TPMT protein deficiency inherited by TPMT*2, TPMT*3A, TPMT*3B or

TPMT*3C. Pharmacogenetics 1999; 9: 641-50.

21 Nishida A, Kubota T, Yamada Y, et al. Thiopurine Smethyltransferase activity in Japanese subjects: metabolic activity of 6-mercaptopurine 6-methylation in different TPMT genotypes. Clin Chim Acta 2002; 323: 147-50.

22 Hon YY, Fessing MY, Pui CH, Relling MV, Krynetski EY, Evans WE. Polymorphism of thiopurine S-methyltransferase gene in AfricanAmericans. Hum Mol Genet 1999; 8: 371-6.

23 Evans WE, Hon YY, Bomgaars $L$, et al. Preponderance of thiopurine S-methyltransferase deficiency and heterozygosity among patients intolerant to mercaptopurine or azathioprine. J Clin Oncol 2001; 19: 2293-301.

24 Tassaneeyakul W, Srimartpirom S, Reungjui S, Chunsung K, Romphruk A, Tassaneeyakul W. Azathioprine-induced fatal myelosuppression in a renal transplant recipient who carried heterozygous TPMT*1/*3C. Transplantation 2003; 76: 265-6.

25 McLeod HL, Pritchard SC. Githang'a J, et al. Ethnic differences in thiopurine methyltransferase pharmacogenetics: evidence for allele specificity in Caucasian and Kenyan individuals. Pharmacogenetics 1999; 9: 773-6.

26 Ameyaw MM, Collie-Duguid ES, Powrie RH, Ofori-Adjei D, McLeod $\mathrm{HL}$. Thiopurine methyltransferase alleles in British and Ghanaian populations. Hum Mol Genet 1999; 8: 367-70. 